\title{
Pre-schoolers suffering from psychiatric disorders show increased cortisol secretion and poor sleep compared to healthy controls
}

\author{
Martin Hatzinger ${ }^{a, b, *}$, Serge Brand ${ }^{b}$, Sonja Perren ${ }^{c}$, Anges von $W y^{d}$, Stephanie Stadelmann ${ }^{e}$, \\ Kai von Klitzing ${ }^{\mathrm{e}}$, Edith Holsboer-Trachsler ${ }^{b}$ \\ ${ }^{a}$ Psychiatric Services Solothum, Department of Adult Psychiatry, Solothurn, Switzerland \\ ${ }^{b}$ Psychiatric Hospital of the University of Basel, Depression and Sleep Research Unit, Wilhelm Kleinstr. 27, 4012 Basel, Switzerland \\ "Jacobs Center for Productive Youth Development, University of Zurich. Switzerland \\ institute of Psychology. University of Zurich. Switzerland \\ ${ }^{2}$ Department of Child and Adolescent Psychiatry, Psychotherapy, and Psychosomatics, University of Leipzig, Germany
}

Keywords:

Cortisol

Sleep

Actigraphy

Pre-schoolers

Psychiatric disorders

\begin{abstract}
Background: Various studies of child cortisol secretion and sleep show a close association between poor sleep, deterioration of the HPA axis and unfavorable psychological functioning. However, there is little evidence as to whether these associations are clearly present in pre-school children suffering from psychiatric disorders.

Method: A total of 30 pre-schoolers suffering from psychiatric disorders (anxiety, adjustment disorders, emotional and attachment disorder: hyperactivity or oppositional disorder) and 35 healthy controls took part in the study. Saliva cortisol secretion was assessed both at baseline and under challenge conditions. Sleep was assessed via activity monitoring for seven consecutive days and nights, using a digital movement-measuring instrument. Parents and teachers completed questionnaires assessing children's cognitive, emotional and social functioning. The Berkeley Puppet Interview provided child-based reports of cognitive-emotional processes.

Results: Compared to healthy controls, children suffering from psychiatric disorders had much higher cortisol secretion both at baseline and under challenge conditions. Sleep was also more disturbed, and parents and teachers rated children suffering from psychiatric disorders as cognitively, emotionally and behaviorally more impaired, relative to healthy controls. Children with psychiatric disorders reported being more bullied and victimized.

Conclusions: In five-year old children the presence of psychiatric disorders is reflected not only at psychological, social and behavioral, but also at neuroendocrine and sleep-related levels. It is likely that these children remain at increased risk for suffering from psychiatric difficulties later in life.
\end{abstract}

\section{Introduction}

More than $50 \%$ of psychiatric disorders emerge before the age of 15 years (Paus et al., 2008; Giedd, 2008). In Germany, hospitalizations of children and adolescents diagnosed with psychiatric disturbances increased by $38.1 \%$ between 2000 and 2007 (Holtmann et al., 2010). Thus, it would appear that psychiatric disorders in children and adolescents (that is, severe emotional, cognitive, behavioral and social difficulties) are becoming more

\footnotetext{
* Corresponding author. Psychiatric Adult Services of Solothurn, Switzerland Tel: +413262714 50; fax: +41326271466 .

E-mail address: martin.hatzinger@spital.so.ch (M. Hatzinger).
}

common and constitute a growing concern for children, parents, teachers, and for the public health system.

Additionally, there is virtually no psychiatric disorder which is not also associated with poor sleep. To give a few examples, in adults, impaired sleep has been observed in patients suffering from depressive disorders (Schüle et al., 2001; Pillai et al., 2011), anxiety disorders (Koffel and Watson, 2009), specific phobias (Brand et al.. 2011a), posttraumatic stress disorders (McLay et al., 2010), and bipolar disorders (Murray and Harvey, 2010; Smith et al,, 2005). Similarly, an association between poor sleep and poor psychological functioning is also apparent in infants suffering from infantile colic (Brand et al., 2011b), healthy pre-schoolers (Hatzinger et al., 2008, 2010), children (Gregory and Sadeh, 2011), children with ADHD (Kirov et al., 2007; Cortese et al., 2006), adolescents (Lund et al., 
2010), and adolescents suffering from bipolar disorders (Heiler et al. 2011; Lorberg et al., 2010), alcohol abuse (Gromov and Gromov, 2009; Lorberg et al., 2010) and depressive disorders (Lofthouse et al., 2009; see Brand and Kirov 2011; Kirov and Brand, 2011; Ivanenko, 2008 for overview). Of note, restorative and adequate sleep is fundamental to brain plasticity (Dang-Vu et al., 2006) and brain development (Peiraro and Algarin, 2007). Thus, chronic sleep disturbances and neuronal loss during childhood seem to be causally related (Jan et al., 2010). Importantly, data from longitudinal studies indicate that for instance sleep difficulties between the ages three and five years predict early onset of any use of alcohol, marijuana, andillicit drugs, as well as early onset of occasional or regular use of cigarettes by age 12 to 14 (Wong et al., 2004). Likewise, 9-year old children reporting chronic insomnia were at increased risk of developing adverse physical and mental health consequences five years later, along with maladaptive lifestyle coping strategies such as smoking and alcohol consumption (Zhang et al., 2011). Moreover, Gregory et al. $(2005,2009)$ were able to show that sleep problems during childhood increased the risk of developing anxiety and depressive disorders in adulthood. These studies, therefore, suggest that severe sleep problems in pre-schoolers and older children do persist and predict poor mental health not only in early and midadolescence, but also in early adulthood.

In addition to evidence of a relation between sleep and psychological functioning, current concepts suggest that psychophysiological arousal is related to poor sleep. In this regard, one of the most studied and investigated outcome variables of psychophysiological arousal is cortisol secretion, reflecting hypothalamus-pituitary-adrenocorticalaxis activation (HPAAA). There is evidence that poor sleep is associated with increased cortisol secretion (Buckley and Schatzberg, 2005; Steiger, 2007) both in healthy adults (Hori et al., 2011) and adults suffering from specific phobias (Brand et al., 2011a), but also much earlier in life, in infants suffering from infantile colic (Brand et al., $2011 \mathrm{~b}$ ), in healthy though sleep-deprived pre-schoolers (Hatzinger et al., 2008, 2010; Raikkönen et al., 2010), and in sleep-deprived healthy adolescents (Zeiders et al., 2011).

Moreover, there is compelling evidence that HPA AA is compromised among those with mental disorders (for review, see Holsboer and Ising, 2010; Jezova and Hlavacova, 2008; Wolkowitz et al., 2010; de kloet et al., 1998). For example, elevated cortisol levels have been observed in adults suffering from major depressive disorders (Schüle et al., 2001; Pillai et al., 2011; Heim et al., 2008), posttraumatic stress disorders (McFarlane et al., 2011), specific phobias (Brand et al., 2011a), and bipolar disorders (Steen et al., 2011). HPA AA has also been observed to vary with psychological functioning and psychiatric disorders in children and adolescents. However, the direction of association seems more complex. A decrease in HPA AA has been observed in boys with attentiondeficit/hyperactivity disorder and disruptive behavior problems (Stadler et al., 2011), in children with ADHD (Pesonen et al., 2011), and more generally in children with externalizing problems, (i.e., aggressive or other antisocial behavior; Flinn and England, 1997; Moss et al., 1995; Haltigan et al., 2011). In contrast, Hatzinger et al. (2007) were able to show that in 5-years old boys with hyperactivity/impulsivity and emotional problems HPA system activity was significantly increased. Furthermore, cross-sectional studies have shown task-related increases in salivary cortisol to be linked to a pattern of negative control-related beliefs (that is, low selfperceived ability to cope with stressful situations; Granger et al., 1996) as well to with internalizing symptoms, which are typically related to disturbances in mood and anxiety (Zahn-Waxler et al., 2000). Similarly, high basal levels of cortisol (particularly in the early morning) and heightened stress responses (that is, strong behavioral reactions to unfamiliar events) have been noted in young children described as behaviorally inhibited and shy (Kagan et al., 1988; Schmidt et al., 1997; Nachmiaś et al., 1996; Watamura et al., 2003). Greatly increased HPA AA has also been observed in children suffering from separation anxiety disorders, relative to healthy controls (Brand et al., 2011c), as well as in children suffering from social phobia when starting school (Russ et al., in press). Finally, studies of depression in childhood lend support to the view that depressive symptoms and increased HPA AA are closely related in pre-schoolers (Luby et al., 2003; see Lopez-Duran et al., 2009 for review).

Taken together, numerous publications suggest that poor sleep is related to poor mental functioning and psychophysiological hyperarousal as reflected in raised cortisol secretion. Data from longitudinal studies further indicate that untreated sleep difficulties during early and mid-childhood predict poor mental development. However, no data related to mental health and sleep are concomitantly available from pre-schoolers suffering from psychiatric disorders. But given the high risk of these young children reporting psychological difficulties in later life, we believe that basic data on psychoendocrinology (i.e., cortisol secretion), mental health and sleep are essential for both intervention and prediction.

The following four hypotheses were formulated. First, following Luby et al. (2003), Lopez-Duran et al. (2009), Russ et al. (in press) Kagan et al. (1988), Schmidt et al. (1997), Nachmias et al. (1996) Watamura et al. (2003) and Brand et al. (2011c), we expected higher cortisol secretion both at baseline and during a challenge condition in children with psychiatric disorders as compared to healthy controls. Second, following Kirov et al. (2007), Räikkönen et al. (2010), Hatzinger et al. (2008, 2010), Hori et al. (2011), and Zeiders et al. (2011), we anticipated poor sleep patterns in children with psychiatric disorders as compared to healthy controls. Third by definition, we expected to find greater emotional and behavioral difficulties in children with psychiatric disorders as compared to healthy controls. Last, we anticipated that unfavorable psychological functioning, poor sleep and increased HPA AA would be associated in the sample of children with psychiatric disorders.

\section{Methods}

\subsection{Participants}

A total of 35 of children suffering from emotional and behavioral difficulties were referred from residents and pediatricians to the Department of Child and Adolescent Psychiatry, University of Basel (Switzerland) for further diagnoses and treatment. Parents of 30 children consented to participation in the study. Average age was 4.84 years $(S D=.49) ; 7$ were girls and 23 were boys (gender ratio: $7 / 23=.30$ ). Based on ICD-10 codifications, the following diagnoses were made: F40.9: Phobic anxiety disorders, unspecified $(n=2)$; F41.9: Anxiety disorder, unspecified $(n=2) ; \mathrm{F} 43$; Reaction to severe stress, and adjustment disorders $(n=4)$ (clustered to and termed as anxiety and adjustment disorders; $n=8$ ); F90: Hyperkinetic disorder $(n=3)$; F91: Conduct disorder $(n=5)$ (clustered to and termed as behavioral disorders; $n=8$ ); F93.9: Childhood emotional disorder, unspecified $(n=3)$; F94.9: Childhood disorder of social functioning, unspecified $(n=6)$ (clustered to and termed as emotional and social disorders; $n=9$ ); F98.9: Unspecified behavioral and emotional disorders with onset usually occurring in childhood and adolescence ( $n=5$ ) (clustered to and termed as other psychiatric disorders: $n=5$ ).

To provide a comparison group of healthy controls, data were used for 35 children from a larger sample of 102 (see Hatzinger et al., $2007,2008,2010$ for a detailed description of the entire sample). The selected group consisted of nine girls and 26 boys (gender ratio: $9 / 26=.34)$, and mean age was $M=4.91$ years $(S D=.48$ ). For selection, 
the following algorithms were employed: age, gender, normal sleepers (see Hatzinger et al., 2008, 2010); average cortisol secretion under baseline and challenge conditions (see Hatzinger et al., 2007) and average values on the Strength and Difficulties Questionnaire (Goodman, 1997). Thus, the intention was to compare children from the clinical sample with healthy controls averaged with respect to age, gender, sleep, cortisol secretion and behavior.

All assessments of children were performed during regular kindergarten terms.

The purpose and experimental details of the study were fully explained to the children and their parents. Before a child entered the study, both child and parents had to give their consent, and parents were asked to sign an informed consent form. The experimental protocol was approved by the local ethics committee.

\subsection{Sleep assessment}

As described in detail elsewhere (Hatzinger et al., 2008), sleep was assessed with two instruments. First, parents were trained to keep a daily log of their child's sleep. In this they recorded the day of the week, the time the child went to bed and when she or he woke up. Additionally, parents noted when the actigraph was not worn (e.g., when swimming or bathing), if the child was napping, and if any change in sleep routine occurred. The information derived from the daily sleep log was also used to check for possible discrepancies and missing data from the actigraph.

Second, given that subjective reports of children's sleep might be biased ( $c$. Dayyat et al., 2011), sleep was objectively assessed under in-home conditions for seven consecutive days and nights. According to Sadeh et al. (1991), in-home sleep assessment of children has the advantage that sleep does not seem to be negatively affected. Children wore a digital movement-measuring instrument (actigraph; Somnowatch ${ }^{(\bullet)}$ : Somnomedics, Randersacker, Germany) on the wrist of the non-dominant hand. This commercially available tool has the dimension of a wristwatch, and it registers every movement greater than $.012 \mathrm{~g}$ in a bi-axial direction. The data, recorded in 30-s intervals, were digitally integrated and afterward translated into sleep measures using the software program (based on the sleep/wake algorithm as described by Gorny et al., 1997) provided by Somnowatch ${ }^{\circledR}$. Somnomedics, Germany. First, parents and children were instructed in how to wear and use the device. They were trained to push the 'marker button' to indicate the beginning and the end of the night; that is to say, in the evening at lights-out a parent or the child pushed the button to indicate bedtime. In the morning, as soon as the child was awake, the child pushed the button again to indicate the sleep end time. If unsure whether they had pushed the button firmly enough, they were instructed to push the button a second time. To become accustomed to the wristwatch-like actigraph, children started wearing the instrument during an afternoon. This avoided possible first-night effects, though such effects have not so far been reported with actigraphs ( $c$. Sadeh et al., 1991)

Following Sadeh et al. (2000), the sleep-continuity parameters gathered were: sleep onset latency (SOL), the difference between the first minute of three consecutive minutes of sleep after reported bedtime and the reported bedtime (i. e., the marker indicated by pushing the button in the evening); morning awakening time as the last minute identified as sleep, (i.e., the marker indicated by pushing the button in the morning); the number and the times of awakenings after sleep onset (SO); sleep period time (SPT), that is, the sleep time (minutes) from SOL to morning awakening. The following dependent variables were derived from these parameters: total time asleep (TST), the number of minutes of sleep time excluding all time awake; SOL, SPT, time and number of awakenings after SO, and sleep efficiency (SE), i.e., the ratio of TST to SPT.
Inter-class correlations of night-to-night reliability measures are reported in Table 1 . In summary, night-to-night stability was high (cf. El-Sheikh et al., 2007; Hatzinger et al., 2010), and, except for SOL and SPT during weekdays, exceeded Acebo et al.'s (1999) recommended stability level of 70 . Importantly, no systematic change in stability was observed between weekdays and weekend days (cf. Dahl and Lewin, 2002; Werner et al, 2008). Therefore, the data from all seven consecutive days were combined.

\subsection{HPA system assessment}

\subsubsection{HPA system activity under baseline conditions}

As discussed in detail elsewhere (Hatzinger et al., 2007), morning cortisol levels have been shown to be a reliable biological marker for the HPA activity of children, adolescents, and adults, when measured repeatedly with strict reference to the time of awakening (Pruessner et al., 1997). Therefore, four saliva cortisol samples were taken by the parents after the last night of actigraphy at $0,10,20$, and $30 \mathrm{~min}$ after the child woke. Waking times ranged from 6.00 to $7.15 \mathrm{a} . \mathrm{m}$. The parents were instructed and trained in the saliva sampling method before starting the study. These saliva samples were then collected from parents on weekdays during regular kindergarten terms.

\subsubsection{HPA system activity under psychological stress conditions}

To assess HPA axis responses to psychological challenge, the MacArthur Story Stem Battery (MSSB) was used (see Von Klitzing et al., 2003, and Hatzinger et al, 2007, for detailed description) in preference to the Trier Social Stress Test for Children (TSST-C; Buske-Kirschbaum et al.. 1997; Stadler et al., 2011). In the former, the child's task, which demands high ego involvement, is to continue and/or finish a story. The stories contain stressful events from children's everyday life, such as loss of a family pet, a quarrel between parents, or a moral dilemma. The story stems build up to a dramatic climax, and the child is then asked to show and tell what happens next. The play narratives are videotaped and coded with the MacArthur Narrative Coding system (Von Klitzing et al., 2003). The advantages of the MSSB are that, first, the procedure is validated (e.g., Von Klitzing et al., 2003), second, it can also be used with children who have not yet started school and third and of particular importance, in contrast to the TSST-C, children do not have to know how to calculate.

Five salivary cortisol samplings were made during the MSSBtask; the first sample was taken 10 min before starting the MSSBtask, the second sample 1 min before, the third 20 min after the start, and a fourth at the end, 35 min after starting the MSSB-task. Following a recovery time of about $10 \mathrm{~min}$ the fifth and final MSSBrelated saliva sample was collected. MSSB tests were conducted in the kindergarten (always between 10 and $11 \mathrm{am}$.) and three to ten days prior to the sleep assessment.

Table 1

Inter-class correlations of night-to-night reliability/stability measures, separated for weekdays, weekend days, for weekdays-to-weekend days, and for the entire period of seven consecutive days.

\begin{tabular}{llllll}
\hline & $\begin{array}{l}\text { SPT } \\
(\mathrm{min})\end{array}$ & $\begin{array}{l}\text { TST } \\
(\mathrm{min})\end{array}$ & $\begin{array}{l}\text { SOL } \\
(\mathrm{min})\end{array}$ & $\begin{array}{l}\text { SE } \\
(\%)\end{array}$ & $\begin{array}{l}\text { Time } \\
\text { awakenings } \\
\text { after SO (min) }\end{array}$ \\
\hline Weekdays & .52 & .85 & .57 & .89 & .89 \\
Weekend days & .81 & .81 & .60 & .83 & .79 \\
$\begin{array}{l}\text { Weekdays-to-weekend } \\
\quad \text { days }\end{array}$ & .71 & .85 & .53 & .89 & .90 \\
Total week & .73 & .90 & .57 & .90 & .90 \\
\hline
\end{tabular}

Note: SPT = sleep period time; TST = total sleep time; SOL = sleep onset latency; $\mathrm{SE}=$ sleep efficiency; $S O=$ sleep onset. $N=65$ (clinical sample: $n=30$; healthy controls: $n=35$ ). 


\subsection{Behavioral/emotional assessment}

Teachers and parents assessed children's behavioral and emotional states. These states were also assessed on the basis of children's responses using the Berkley Puppet Interview.

\subsubsection{Teachers' and parents' view of children's behavioral and emotional states}

Parents (mothers, fathers or other legal guardians) and teachers completed the Strengths and Difficulties Questionnaire (SDQ; Goodman, 1997). Children's behavioral/emotional difficulties were assessed on five scales: emotional problems, conduct problems, hyperactivity, peer problems, and prosocial behavior. All mothers and legal guardians completed the questionnaires; of the 65 mothers, 11 were single parents (all of children with psychiatric disorders). Nineteen fathers (all of children with psychiatric disorders) did not complete the questionnaires, leaving 46 questionnaires available from fathers (70.8\%).

\subsubsection{Children's perceptions of their behavioral and emotional states}

The Berkley Puppet Interview (BPI), developed by Measelle et al. (1998), blends structured and clinical interviewing techniques to elicit children's self-perceptions. To link child reports of behavioral/ emotional difficulties with parent and teacher reports we aggregated the original BPI-subscales. The emotional symptoms scale encompasses depression, separation anxiety and over-anxiousness. Conduct problems covers oppositionality/defiance and overt aggression to peers. The hyperactivity/impulsivity scale includes impulsivity together with a single item on inattention. We used the Swiss German translation of the items.

\subsection{Saliva cortisol sampling technique and cortisol analysis}

Saliva samples were obtained using the "Salivette" device for quick and hygienic sampling (Sarstedt, Nümbrecht/Germany). This device consists of a small cotton swab on which the subject chews gently for .5-1 $\mathrm{min}$. The swab then is transferred into a small plastic tube and stored in the freezer. Saliva samples were returned to the laboratory, where samples were centrifuged at $4{ }^{\circ} \mathrm{C}(2000 \mathrm{rpm}$, $10 \mathrm{~min}$ ) and stored at $-20^{\circ} \mathrm{C}$ until assay.

Free salivary cortisol concentrations were analyzed using a time-resolved immunoassay with fluorometric detection "CoatA-Count" Cortisol RIA from DPC (Diagnostics Products Corporation; obtained through $\mathrm{H}$. Biermann $\mathrm{GmbH}_{\text {, Bad Nauheim, Germany) }}$ as described in detail elsewhere (cf. Dressendoerfer et al., 1992). Intra- and inter-assay variabilities were less than $3.01 \%$ and $3.98 \%$, respectively.

For statistical analysis, as a more reliable estimate of the total amount of hormone release, the area-under-the-concentrationtime curve (AUC, arbitrary units) of the morning cortisol levels (MC AUC) was calculated using trapezoidal integration (Forsythe et al., 1969). The AUC total refers to the entire amount of cortisol concentration under the time curve, whereas the AUC basal describes the initial and averaged amount of cortisol secretion over time, as if the HPA axis had not been stimulated; accordingly, the AUC net refers to the difference in cortisol secretion between AUC total and basal (cf. Hatzinger et al., 2007; Heuser et al., 1994).

\subsection{Statistical analyses}

To calculate possible differences in cortisol levels, sleep patterns and behavioral/emotional states between the psychiatric disorders (preliminary calculations), multivariate analyses and a series of one-way ANOVAs were performed with the diagnostic clusters as independent variable and cortisol secretion, sleep patterns and behavioral/emotional states as dependent variables.

To calculate differences in cortisol release between the clinical sample (CS) and the control group (CG), a series of single ANOVAs were performed. Given that there is some evidence that cortisol secretion differs between 5 -years old boys and giris, for these calculations, Gender (males vs. females) was introduced as a factor in addition to Group (clinical sample vs. control group).

A series of single $t$-tests were performed to compare sleep and behavioral/emotional states between the two groups. Where variances were not equal the more robust Welch-test " $w$ " was used (Welch, 1947; Scheffé, 1970). Effect sizes for $t$-tests were calculated following Cohen (1988), with $.49 \geq d \geq .20$ indicating small (i.e., negligible practical importance), $.79 \geq d \geq .50$ indicating medium (i.e., moderate practical importance), and $d \geq .80$ indicating large (i.e., crucial practical importance) effect sizes. Pearson product-moment-correlations were computed between the data from actigraphic sleep assessment, cortisol secretion and behavioral/emotional states (psychological functioning). The distribution of gender and sleep groups was assessed by Chi-square. Test results with an alpha level of below .05 are reported as significant. Statistical analysis was performed using SPSS 19.0 for Windows.

\section{Results}

3.1. Preliminary calculations: cortisol secretion, sleep patterns and emotional/behavioral states as a function of psychiatric diagnoses

To test whether cortisol secretion (baseline in the morning and under challenge conditions), sleep patterns and emotional/behavioral states differed between psychiatric diagnoses (anxiety and adjustment disorders; behavioral disorders; emotional and social disorders; other psychiatric disorders), multivariate analyses and a series of one-way ANOVAs were performed with the diagnostic clusters as independent variable and cortisol secretion, sleep patterns, and emotional/behavioral states ${ }^{1}$ as dependent variables. Table 2 gives the descriptive and inferential statistics.

The main result was that neither cortisol secretion, nor sleep patterns, nor emotional/behavioral states did significantly differ across clusters of psychiatric diagnoses. Therefore, all children diagnosed with a psychiatric disorder were combined into a single 'clinical' sample.

\subsection{Cortisol secretion in children with a psychiatric diagnosis and healthy controls}

To test whether cortisol secretion (baseline in the morning and under challenge conditions) differed between children with a psychiatric diagnosis (clinical sample) and healthy controls (control group), and as a function of gender, a series of two-ways ANOVAs was performed with the factors Group (clinical sample vs. healthy controls) and Gender (females vs. males) as independent variables and cortisol secretion as the dependent variable. Table 3 gives the descriptive and inferential statistics.

Results indicate that baseline cortisol (morning cortisol) was significantly higher in the clinical sample than in the control group. Moreover, compared to males, females had significantly higher cortisol secretion. Importantly, the significant Group $\times$ Gender interaction reflected higher baseline cortisol secretion in girls with psychiatric disorders.

\footnotetext{
1 To reduce the number of analyses, for sleep. TST, SOL and ES were calculated. For emotional/behavioural states, teachers' view of prosocial behavior and the total difficulties score were reported.
} 
Table 2

Cortisol secretion (under baseline and under challenge conditions), sleep patterns and emotional/behavioural states, separately for clusters of psychiatric disorders.

\begin{tabular}{|c|c|c|c|c|c|c|}
\hline & \multicolumn{4}{|l|}{ Clusters } & \multirow[t]{2}{*}{ Statistics } & \multirow[b]{3}{*}{$\begin{array}{l}\text { Wilks-lamda } \\
(9.58 .56)=1.56, p=.25\end{array}$} \\
\hline & $\begin{array}{l}\text { Anxiety and } \\
\text { adjustment } \\
\text { disorders }\end{array}$ & $\begin{array}{l}\text { Behavioral } \\
\text { disorders }\end{array}$ & $\begin{array}{l}\text { Emotional and } \\
\text { social disorders }\end{array}$ & $\begin{array}{l}\text { Other psychiatric } \\
\text { disorders }\end{array}$ & & \\
\hline$N$ & 8 & 8 & 9 & 5 & Multivariate analysis & \\
\hline $\begin{array}{l}\text { Baseline (morning) } \\
\text { AUC basal } \\
\text { AUC total } \\
\text { AUC net }\end{array}$ & $\begin{array}{l}282.50(72.26) \\
320.00(107.70) \\
268.00(135.30)\end{array}$ & $\begin{array}{l}250.75(120.25) \\
356.25(132.55) \\
123.50(118.93)\end{array}$ & $\begin{array}{l}192.89(69.23) \\
466.78(156.11) \\
211.00(118.09)\end{array}$ & $\begin{array}{l}194.24(88.79) \\
417.20(241.76) \\
203.60(106.30)\end{array}$ & $\begin{array}{l}\text { Univariate analyses } \\
F(3,26)=1.84, p=.17 \\
F(3,26)=1.44, p=.25 \\
F(3,26)=1.92, p=.15\end{array}$ & \\
\hline . & 8 & 8 & 9 & 5 & Multivariate analysis & $\begin{array}{l}\text { Wilks-lamda } \\
(9,58.56)=1.74, p=.12\end{array}$ \\
\hline $\begin{array}{l}\text { Challenge (MSSB) } \\
\text { AUC basal } \\
\text { AUC total } \\
\text { AUC net }\end{array}$ & $\begin{array}{r}66.50(33.20) \\
83.75(47.05) \\
.75(37.45)\end{array}$ & $\begin{array}{c}62.37(35.77) \\
58.63(23.22) \\
2.29(7.81)\end{array}$ & $\begin{array}{l}41.67(20.96) \\
63.33(22.21) \\
17.55(19.58)\end{array}$ & $\begin{array}{l}58.40(21.94) \\
81.40(18.61) \\
21.60(16.99)\end{array}$ & $\begin{array}{l}\text { Univariate analyses } \\
F(3,26)=1.21, p=.33 \\
F(3,26)=1.26, p=.31 \\
F(3,26)=1.40, p=.26\end{array}$ & \\
\hline $\begin{array}{l}\text { Sleep variables } \\
\text { TST (min) } \\
\text { SOL (min) } \\
\text { Sleep efficiency }(\%)\end{array}$ & $\begin{array}{c}462.13(19.19) \\
24.25(3.02) \\
84.00(3.07)\end{array}$ & $\begin{array}{c}465.89(14.35) \\
25.87(12.34) \\
85.63(2.67)\end{array}$ & $\begin{array}{r}461.22(9.34) \\
31.11(4.78) \\
81.11(7.56)\end{array}$ & $\begin{array}{l}454.20(23.09) \\
25.40(6.11) \\
83.60(4.50)\end{array}$ & $\begin{array}{l}F(3,26)=1.40, p=.27 \\
F(3,26)=.56, p=.65 \\
F(3,26)=1.19, p=.33\end{array}$ & \\
\hline $\begin{array}{l}\text { SDQ (teachers' view) } \\
\text { Prosocial behavior } \\
\text { Total difficulties score }\end{array}$ & $\begin{array}{l}.95(.42) \\
.89(.35)\end{array}$ & $\begin{array}{l}.89(.36) \\
.86(.12)\end{array}$ & $\begin{array}{l}.81(.43) \\
.95(.51)\end{array}$ & $\begin{array}{l}.94(.32) \\
.93(.67)\end{array}$ & $\begin{array}{l}F(3,26)=1.02, p=.42 \\
F(3,26)=.95, p=.52\end{array}$ & \\
\hline
\end{tabular}

Notes: $N=$ number of children; MSSB $=$ McArthur Story Stem Battery; AUC $=$ area under the curve; net $=$ netto. TST $=$ total sleep time; SOL $=$ sleep onset latency; SPT $=$ sleep period time: $S O=$ sleep onset: mean and standard deviation. $S D Q=S t r e n g t h$ and Difficulties questionnaire.

Cortisol levels under challenge conditions (MSSB; AUC basal and AUC total) were significantly higher in the clinical sample than in the control group.

Overall, the pattern of results showed that the HPA AA (baseline and under challenge conditions) was elevated in children with psychiatric disorders, and in particular in girls with psychiatric disorders.

3.3. Sleep patterns of children with psychiatric disorders (clinical sample) and healthy controls (control group)

To test whether actigraphically assessed sleep patterns differed between children with and without psychiatric disorders, a series of single $t-1 w$-tests were performed comparing the clinical sample and control group. ${ }^{2}$ Table 4 gives the descriptive and inferential statistics.

Compared to healthy controls, children with psychiatric diagnoses had shorter sleep duration, longer sleep onset latency, more awakenings (number of awakenings and duration), and an overall decreased sleep efficiency.

3.4. Psychological functioning as rated by teachers and parents (Strengths and Difficulties Questionnaire; SDQ) of children with psychiatric disorders (clinical sample) and healthy controls (control group)

To test for differences between children with psychiatric disorders and healthy controls in their psychological functioning as rated by teachers and parents, a series of single $t$-tests were performed. Table 5 gives the descriptive and inferential statistics.

As indicated in Table 5, compared to healthy controls, children with psychiatric disorders had significantly more marked

\footnotetext{
2 Preliminary calculations showed that sleep patterns did not systematically differ between females and males ( $t s<1.5$ ); therefore, Gender was not introduced as a further factor. Actigraphic data were available from 28 of the 30 children with psychiatric disorders.
}

emotional symptoms, conduct and peer problems, and hyperactivity, and a higher total difficulties score. With regard to prosocial behavior, compared to parents, teacher ratings for prosocial behavior were lower for children with psychiatric disorders.

3.5. Comparison of children with psychiatric disorders (clinical sample) and healthy controls (control group) with respect to children's view of psychological functioning (Berkley Puppet Interview)

To test for differences in children's view in psychological functioning between those with psychiatric disorders and healthy controls, a series of single $t$-tests were performed. Table 6 give the descriptive and inferential statistics.

Significant mean differences between the clinical sample and healthy controls were found for the following dimension: children with psychiatric disorders reported being bullied more, being more hyperactive, and more victimized; healthy controls reported being more socially inhibited. There were no significant differences on the following dimensions: depressive symptoms, separation anxiety, over-anxiety, oppositional behavior, inattention, impulsivity, overt aggression, and prosocial behavior.

\subsection{Relations between sleep, cortisol secretion and psychological functioning}

Table 7 gives the matrix of intercorrelations (Pearson's correlation coefficients) between cortisol, sleep and psychological functioning for the clinical sample. ${ }^{3}$ Though correlation coefficients did not reach statistical significance, the general pattern of results was in the expected direction; that is to say, poor sleep, increased cortisol secretion and increased psychosocial difficulties were interrelated.

\footnotetext{
${ }^{3}$ The sample with healthy controls was not included in these calculations; healthy controls were selected on the basis of their stability and regularity with respect to cortisol secretion, sleep and psychological functioning, and therefore high variances leading to meaningful correlations could not be expected.
} 
Cortisol secretion under baseline and under challenge conditions separately for the clinical sample and healthy controls and for gender

\begin{tabular}{|c|c|c|c|c|c|c|c|}
\hline & \multicolumn{4}{|l|}{ Groups } & \multirow{2}{*}{\multicolumn{3}{|c|}{ Statistics }} \\
\hline & \multicolumn{2}{|l|}{ Clinical sample } & \multicolumn{2}{|c|}{ Healthy controls } & & & \\
\hline & Females & Males & Fermales & Males & Group & Gender & $\begin{array}{l}\text { Group } \times \text { gender } \\
\text { interaction }\end{array}$ \\
\hline$N$ & 7 & 23 & 9 & 26 & \multicolumn{3}{|c|}{ Wilks-Lamda $(9.58 .56)=1.56 . p=.25$} \\
\hline \multicolumn{8}{|c|}{ Baseline (morning) } \\
\hline AUC basal & $384.99(115.68)$ & $211.78(182.39)$ & $46.24(38.94)$ & $32.32(29.70)$ & $76.41^{* *}, \eta^{2}=.40$ & $9.96^{* *}, \eta^{2}=.08$ & $7.22^{* *}, \eta^{2}=.06$ \\
\hline AUC total & $736.90(217.72)$ & $407.54(195.88$ & $80.36(45.39)$ & $52.60(30.46)$ & $121.65^{* 4 \frac{3}{\eta}} \cdot \eta^{2}=.51$ & $15.16^{* * *} \cdot \eta^{2}=.12$ & $10.82^{* * *}, \eta^{2}=.09$ \\
\hline AUC net & $351.92(123.75)$ & $195.76(144.37)$ & $34.12(35.43)$ & $20.29(23.61)$ & $71.64^{* * *}, \eta^{2}=.07$ & $8.51^{* *} \cdot \eta^{2}=.07$ & $5.96^{* *}, \eta^{2}=.05$ \\
\hline \multicolumn{8}{|c|}{ Challenge (MSSB) } \\
\hline AUC basal & $54.48(49.68)$ & $62.00(39.46)$ & $23.30(25.52)$ & $18.11(18.05)$ & $30.68^{* * *} \cdot \eta^{2}=.17$ & $.03, \eta^{2}=.00$ & $.88, \eta^{2}=.01$ \\
\hline AUC total & $56.48(23.68)$ & $73.84(59.95)$ & $25.32(22.89)$ & $23.18(18.64)$ & $29.43^{* * *}, \eta^{2}=.16$ & $1.02, \eta^{2}=.01$ & 1.67. $\eta^{2}=.01$ \\
\hline AUC net & $2.00(27.97)$ & $11.84(30.81)$ & $2.08(23.46)$ & $5.07(20.45)$ & $.30, \eta^{2}=.002$ & $1.09, \eta^{2}=.01$ & $.30, \eta^{2}=.00$ \\
\hline
\end{tabular}

Notes: Degrees of freedom in all cases: 3,$26 ; N=$ number of children: MSSB = McArthur Story Stem Battery: AUC $=$ area under the curve; net $=$ netto: ${ }^{*}=p<.05 ;{ }^{* *}=p<.01$ $* * *=p<.001, \eta^{2}=$ partial eta squared.

\section{Discussion}

The main findings of the present study are that, compared to healthy controls, children diagnosed with a psychiatric disorder have higher cortisol secretion both at baseline and during challenge conditions, poorer sleep and more unfavorable psychological functioning. The findings add to the current literature in that we were able to show that by the age of five psychiatric disorders are associated with poor sleep, higher cortisol secretion and poor behavioral and emotional adjustment.

Four hypotheses were formulated and each of these is now considered in turn.

With the first hypothesis we anticipated higher cortisol secretion in children with a psychiatric disorder (clinical sample), relative to healthy controls (control group), and the data fully confirmed this. Our findings are in this respect consistent with the numerous studies reporting a close relationship between a deteriorated HPA axis and psychiatric disorders in children and adolescents (cf. Luby et al., 2003; Lopez-Duran et al., 2009; Russ et al., in press; Kagan et al., 1988; Schmidt et al., 1997; Nachmias et al., 1996; Watamura et al., 2003; Brand et al., 2011c). However, the present data do add to the existing literature in showing that the relation between deteriorated HPA axis and psychiatric disorders can be found in pre-schoolers. Importantly, increased cortisol levels were observed both under baseline (morning cortisol) and challenge conditions. Thus, if we consider cortisol secretion as a reflection of individuals' adaptation to internal and external stressors, children with psychiatric disorders show continuous psychophysiological hyperarousal, probably as an adaptation to constant intrapsychic and psychosocial stressors (cf. Brand et al., 2011c for children suffering from separation anxiety disorders).

Second, we hypothesized that there would be poor sleep patterns in children with psychiatric disorders as compared to healthy controls, and data also confirmed this prediction Therefore the present findings do fit with those from numerous previous publications (cf. Kirov et al., 2007; Hatzinger et al., 2008, 2010; Hor et al., 2011; Zeiders et al., 2011), though again data do add something to the existing literature in showing that this pattern of associations is also found in pre-schoolers with psychiatric disorders.

Our third hypothesis was that there would be greater emotional and behavioral difficulties in children with psychiatric disorders as compared to healthy controls, and again the data were consistent with this hypothesis. Importantly the pattern of results holds true irrespective of the source of data, that is, irrespective of whether teachers, parents or the children themselves rated psychological functioning. We note that children with psychiatric disorders, relative to healthy controls, felt bullied and victimized (see Table 6 ) Being bullied was associated with increased cortisol secretion and poor sleep (see Table 7). Again, we conclude that increased HPA AA may reflect an effort to cope with psychosocial challenges. And, more generally speaking, we suggest that by as early as five years of age psychiatric disorders reflect a bio-psychosocial imbalance (cf. Engel's seminal work, 1977).

Last, we anticipated that unfavorable psychological functioning, poor sleep and increased HPA AA would be associated in the sample of children with psychiatric disorders. As summarized in Table 7 and discussed above, the direction of the correlations was consistent with our prediction though the correlations did not consistently reach statistical significance.

The overall pattern of results suggests that a close relationship between poor sleep, elevated cortisol secretion and poor psychological functioning is already apparent at pre-school age among children suffering from psychiatric disorders. But how should we explain this "triad"? Four theoretical frameworks are proposed: a) Riemann et al.'s model of bottom-up processes to explain poor

Table 4

Sleep measures (means and standard deviations) separated by children with psychiatric disorders and healthy controls.

\begin{tabular}{|c|c|c|c|}
\hline & \multicolumn{2}{|l|}{ Groups } & \multirow{2}{*}{$\frac{\text { Statistics }}{t \text {-tests or } w \text {-tests }}$} \\
\hline & $\begin{array}{l}\text { Children with } \\
\text { psychiatric disorders } \\
n=28\end{array}$ & $\begin{array}{l}\text { Healthy controls } \\
n=35\end{array}$ & \\
\hline TST (min) & $461.79(13.48)$ & $543.49(28.39)$ & $w(50.77)=15.04, p=.000, d=3.69$ \\
\hline $\mathrm{SOL}(\mathrm{min})$ & $26.39(8.01)$ & $12.89(4.09)$ & $w(38.12)=8.13, p=.000, d=2.12$ \\
\hline $\mathrm{SPT}(\min )$ & $525.96(30.34)$ & $554.89(29.26)$ & $t(61)=3.82, p=.000, d=.87$ \\
\hline Time awakenings after SO (min) & $23.46(4.23)$ & $7.45(3.19)$ & $w(49.03)=16.61, p=.000 . d=4.27$ \\
\hline Number of awakenings after So & $5.54(2.53)$ & $1.97(.80)$ & $w(31.17)=7.18, p=.000, d=1.90$ \\
\hline Sleep efficiency (\%) & $83.32(4.98)$ & $94.01(1.73)$ & $w(32.24)=10.83, p=.000, d=2.87$ \\
\hline
\end{tabular}

Note. TST = total sleep time: $\mathrm{SOL}=$ sleep onset latency; SPT = sleep period time; $\mathrm{SO}=$ sleep onset; mean and standard deviation 
Table 5

Psych olagical functioning (Strengths and Difficulties Questionnaire; SDQ) as rated by teachers and parents and separately by children with psychiatric disorders and healthy controls.

\begin{tabular}{|c|c|c|c|}
\hline & \multicolumn{2}{|l|}{ Groups } & \multirow{2}{*}{$\frac{\text { Statistics }}{\text { t-tests }}$} \\
\hline & $\begin{array}{l}\text { Children with } \\
\text { psychiatric } \\
\text { disorders } n=30\end{array}$ & $\begin{array}{l}\text { Healthy } \\
\text { controls } \\
n=35\end{array}$ & \\
\hline \multicolumn{4}{|l|}{ Teachers' ratings } \\
\hline Emotional symptoms & $.80(.54)$ & $.33(.39)$ & $6.42^{* * *}, d=.99$ \\
\hline Conduct problems & $.43(.43)$ & $.19(.32)$ & $3.72^{* * *}, d=.63$ \\
\hline Hypenctivity & $.97(.64)$ & $.55(.53)$ & $4.25^{* * *}, d=.71$ \\
\hline Peer problems & $.76(.49)$ & $.35(.38)$ & $5.87^{* * *}, d=.94$ \\
\hline Prosocial behavior & $.91(.51)$ & $1.48(.40)$ & $7.71^{* * *}, d=1.24$ \\
\hline Total difficulties score & $.74(.32)$ & $.35(.28)$ & $7.46^{* * *}, d=1.30$ \\
\hline \multicolumn{4}{|l|}{ Parents' ratings } \\
\hline Emotional symptoms & $.79(.53)$ & $.35(.38)$ & $5.65^{* * *}, d=.95$ \\
\hline Conduct problems & $.63(.35)$ & $.41(.32)$ & $3.47^{* * *}, d=.65$ \\
\hline Hyperactivity & $1.01(.53)$ & $.59(.43)$ & $4.93^{* * *}, d=.87$ \\
\hline Peer problems & $.57(.49)$ & $.28(.33)$ & $4.18^{* * *} \cdot d=.69$ \\
\hline Prosocial behavior & $1.41(.41)$ & $1.48(.35)$ & $1.06, d=.18$ \\
\hline Total difficulties score & $.79(.37)$ & $.41(.25)$ & $6.53^{* * *}, d=1.20$ \\
\hline
\end{tabular}

Notes. Degrees of freedom: 61 in all cases. Higher scores reflect positions closer to the pole defining the dimension; e.g., As rated by teachers, children with psychiatric disorders had more peer problems (.76) compared to healthy controls (.35): children with psychiatric disorders showed displayed less prosocial behavior (.91) than healthy controls $(1.48){ }^{*}=p<.05 ;^{* *}=p<.01,^{* * *}=p<.001$.

sleep; b) Perlis et al.'s top-down processes to explain poor sleep; c) the concept of impaired prefrontal functioning related to sleep loss, and d) an interactional model taken from developmental psychology (Patterson et al., 1989) and adapted to current data.

a) To explain why psychological processes and sleep might reciprocally interact, Riemann et al. (2010) advanced a bottom-up process in which precipitating stressors can trigger a (genetically) determined dysfunction of sleep-wake regulating neural circuits. As a result, psychophysiological arousal increases, leading to disrupted sleep and disturbed cognitive-emotional processes. For the present sample, our speculation is that children with a (genetic) disposition to unfavorable sleep-wake-pattern regulation, and experiencing current stressors such as being bullied and victimized, may be particularly at risk for both poor sleep and further negative cognitive-emotional processes. In this view, Kirov et al. (2011), for instance, have discussed the reasons for apparently contrasting REM-sleep findings in children with ADHD (increase

Table 6

Children's view of psychological functioning (Berkley Puppet Interview). separately by children with psychiatric disorders and healthy controls.

\begin{tabular}{|c|c|c|c|}
\hline & \multicolumn{2}{|l|}{ Groups } & \multirow{2}{*}{$\frac{\text { Statistics }}{t \text {-tests }}$} \\
\hline . & $\begin{array}{l}\text { Children with } \\
\text { psychiatric } \\
\text { disorders } n=30\end{array}$ & $\begin{array}{l}\text { Healthy } \\
\text { controls } \\
n=35\end{array}$ & \\
\hline Depressive symptoms & $5.09(.60)$ & $5.19(.76)$ & $.75, d=.14$ \\
\hline Separation anxiety & $4.80(.84)$ & $4.87(1.02)$ & $.39, d=.07$ \\
\hline Over-anxiety & $4.68(.85)$ & $4.97(.81)$ & $1.75, d=.35$ \\
\hline Oppositional behavior & $5.07(.84)$ & $5.27(.88)$ & $1.18, d=.23$ \\
\hline Inattention & $4.37(2.02)$ & $4.95(1.77)$ & 1.68. $d=1.31$ \\
\hline Impulsivity & $4.62(1.12)$ & $4.93(.91)$ & $1.67 . d=.30$ \\
\hline Being bullied & $4.76(1.25)$ & $4.08(1.53)$ & $2.73^{* *}, d=.49$ \\
\hline Social inhibition & $4.11(1.03)$ & $4.54(1.00)$ & $2.21^{*}, d=.42$ \\
\hline Overt aggression & $4.98(.82)$ & $5.21(.85)$ & $1.43, d=.27$ \\
\hline Victimization & $3.92(1.53)$ & $3.23(1.25)$ & $2.73^{* *}, d=.49$ \\
\hline Prosocial behavior & $4.46(1.07)$ & $4.62(.97)$ & $.86 . d=.17$ \\
\hline
\end{tabular}

Notes. Arbitrary units; degrees of freedom: 61 in all cases. Higher scores reflect positions closer to the pole defining the dimension. ${ }^{*}=p<.05 ;^{* *}=p<.01$, ${ }^{* * *}=p<.001$ and decrease) across studies. To reconcile these apparently contradictory results, Kirov et al. (2007, 2011) suggested the concept of bidirectional influences: given the relative importance of REM-sleep for elaborating procedural and emotional processes, it seems plausible that children suffering from $A D H D$ and having adverse psychosocial experiences need even more REM-sleep for the elaboration of cognitive-emotional information. On the other hand, if REM-sleep is limited and the associated elaboration of cognitive-emotional processes is poor, children with ADHD are at increased risk of not sufficiently learning from their experiences and therefore at risk of repeating the same patterns of dysfunctional behavior in social contexts. Taken together, one might argue that unfavorable daily psychosocial experiences can lead to increased psychophysiological arousal, which in turn disrupts sleep and associated processes of cognitive-emotional elaboration. Moreover, following Riemann et al.'s model of bottom-up processes, one might claim that current psychiatric disorders are the result of stressors which lead to psychophysiological arousal and poor sleep (see Baglioni et al., 2010 for extensive overview).

b) Complementary to the bottom-up processes proposed by Riemann et al. (2010), Perlis et al. (1997) postulated a topdown process: cortical hyperarousal, experienced subjectively as cognitive hyperarousal such as intrusive thoughts or dysfunctional beliefs during sleep, may lead to increased autonomic arousal, which in turn disrupts sleep. Poor sleep, however, has a strong negative impact on daily functioning. leading therefore to further psychological and social difficulties, such as those regularly experienced in children with psychiatric disorders. In this regard - most dramatically children in the clinical sample reported being bullied and victimized more; this observation fits very well with the above assumptions outlined above. Most importantly, the present results seem to mirror the findings of Sourander et al. (2009): Children who are prone to developing psychiatric disorders are also engaged in behaviors during early childhood making them more likely to be victims of bullying. To illustrate how psychological processes influence the HPA AA, Born et al. (1999) instructed 15 healthy young adults deliberately to determine when they would wake up, and results showed that plasma cortisol secretion increased in parallel with approach to the chosen time of awakening. Thus, this study is a good example of how psychological processes can produce objective and observable neuroendocrine changes. Likewise, we suggest that, in our sample, internal and external stimuli, cognitively and emotionally processed as threatening or challenging, lead to a continuously increased psychophysiological activation and neuroendocrine activity of cortisol secretion.

c) In recent years, neuroimaging research on sleep has made dramatic advances. Yoo et al. (2007) were able to show that under sleep deprivation an increase in amygdala reactivity was associated with a decrease of neuronal activity in the medialprefrontal cortex, a region known to exert top-down control of the limbic area, and known to regulate and modulate emotional responses as appropriate to the context. In the same vein, Drummond et al. (1999) and Muzur et al. (2002) were able to show that sleep deprivation influences cognitive control and frontal executive functions in general. Accordingly, Silk et al. (2007) claimed that adequate sleep seems to contribute strongly to improved affect regulation through enhanced prefrontal cortex (PFC) functioning. Likewise, though speculative, we propose that in children with psychiatric disorders poorer sleep may reduce affect regulation, resulting in more psychosocial difficulties. Intervention studies provide further 
Table 7

Cotrelations (Pearson's correlation coefficients) between cortisol secretion (baseline and under challenge conditions), sleep and psychological functioning in the clinical sample $(n=30)$

\begin{tabular}{|c|c|c|c|c|c|c|c|c|c|c|c|c|c|c|}
\hline & \multirow[b]{3}{*}{ Cortisol } & \multicolumn{6}{|c|}{ Cortisol } & \multirow{2}{*}{\multicolumn{3}{|c|}{ Sleep }} & \multicolumn{4}{|c|}{ Psychological functioning } \\
\hline & & \multicolumn{3}{|c|}{ Baseline } & \multicolumn{3}{|c|}{ Challenge condition } & & & & \multicolumn{2}{|c|}{ Teachers' view } & \multicolumn{2}{|c|}{ Children's view } \\
\hline & & 1 & 2 & 3 & 4 & 5 & 6 & 7 & 8 & 9 & 10 & 11 & 12 & 13 \\
\hline 1 & AUC basal & - & $.56^{* *}$ & $.62^{* *}$ & .23 & .15 & .10 & -.12 & -.20 & .21 & $.31^{*}$ & $-.30^{*}$ & $.35^{*}$ & $.31^{*}$ \\
\hline 2 & AUC total & & - & $.59^{* * *}$ & .21 & .10 & .09 &.- .12 & $-.30^{*}$ & .29 & $.42^{*}$ & -.19 & $.34^{*}$ & $.32^{*}$ \\
\hline 3 & $\begin{array}{l}\text { AUC netto } \\
\text { Challenge conditions }\end{array}$ & & & - & .21 & .12 & .13 & -.09 & -.19 & $.32^{*}$ & $.31^{*}$ & -.29 & .26 & .21 \\
\hline 4 & AUC basal & & & & - & $.50^{*}$ & $.47^{*}$ & -.11 & -.11 & .21 & .28 & -.09 & .25 & .24 \\
\hline 5 & AUC total & & & & & - & .23 & -.05 & -.23 & .23 & .19 & -.05 & .19 & .18 \\
\hline 6 & $\begin{array}{l}\text { AUC netto } \\
\text { Sleep }\end{array}$ & & & & & & - & -.15 & -.22 & .29 & .21 & .02 & .22 & .12 \\
\hline 7 & Sleep efficiency & & & & & & & - & $.54^{* *}$ & $-.66^{* *}$ & $-.34^{*}$ & .27 & $-.32^{*}$ & $-.35^{*}$ \\
\hline 8 & TST & & & & & & & & - & $-.49^{* *}$ & -.25 & $.31^{*}$ & -.19 & -.25 \\
\hline 9 & $\begin{array}{l}\text { SOL } \\
\text { Psychological functioning } \\
\text { Teachers' view }\end{array}$ & & & & & & & & & - & $.34^{*}$ & -.11 & $.29^{*}$ & -.02 \\
\hline 10 & Overall problem score & & & & & & & & & & - & $-.49^{* *}$ & $.34^{*}$ & $.34^{*}$ \\
\hline 11 & $\begin{array}{l}\text { Prosocial behavior } \\
\text { Children's view }\end{array}$ & & & & & & & & & & & - & $-.31^{*}$ & .06 \\
\hline $\begin{array}{l}12 \\
13\end{array}$ & $\begin{array}{l}\text { Being bullied } \\
\text { Hyperactivity }\end{array}$ & & & & & & & & & & & & - & $\begin{array}{l}.35^{*} \\
-\end{array}$ \\
\hline
\end{tabular}

evidence for this proposition. After one week of extending sleep by $1 \mathrm{~h}$, young children showed parent-reported improvements with respect to hyperactivity, anxiety, ADHD and psychiatric symptoms (Crabtree et al., 2007). Children suffering from obstructive sleep apnea (OSA) showed significantly increased parent-reported internalizing and externalizing problems, relative to healthy controls. Six months after tonsillectomy, OSAs were no longer observed, and, most importantly, internalizing and externalizing problems improved and no longer differed from those displayed by healthy controls (Tran et al., 2005).

To conclude, even if the present cross-sectional study design does not allow causal conclusions, we hold that poor sleep might have least comexisted with the onset of psychosocial disturbances, while current poor sleep might maintain psychiatric disorders. In this regard, longitudinal studies (Gregory et al., 2005, 2009; Wong et al., 2004) lend further support to the notion that sleep disturbances during childhood predict poor adjustment during adolescence and early adulthood.

d) Patterson et al.'s model for the development and maintenance of children's coercive behavior (Patterson et al., 1989) may be also applicable to our study question. This model claims that adverse parenting styles such as high behavioral and responsive inconsistency, low control and lack of warmth interact with a child's negative temperament (e.g., easily irritable, irascible, low tolerance of frustration) and behavior (e.g., oppositional-aggressive; hyperactive), and poor intellectual skills (e.g., low degree of fast and accurate information processing) and vice versa. Thus, this model proposes a reciprocal impact and feedback loop between parenting style and child's psychosocial, intellectual and behavioral characteristics over time. Similarly, we may speculate that, over time, poor sleep, unfavorable psychosocial experiences and psychophysiological arousal (i.e., increased cortisol secretion) reciprocally influence one another, as our data seem to indicate. In other words, one may claim that neuroendocrine sleep regulation, sleep, and psychosocial experiences, along with psychiatric difficulties might be "swept" into a sort of "negative spiral" in which reciprocal effects occur. Most importantly, there is evidence that sleep deprivation leads to an increase in cortisol secretion (cf. Buckley and Schatzberg, 2005; Steiger, 2007; Hori et al. 2011; Räikkönnen et al., 2010), thus further contributing to an up-regulation of the psychophysiological system and hyperarousal.

Taken together, several theoretical and evidence-based frameworks provide explanations as to how and why poor sleep, increased cortisol secretion and poor psychological functioning (in the present case psychiatric disorders) may emerge concurrently.

Despite the new findings, several issues warrant against overgeneralization. First, sample sizes were rather small, though, in addition to p-values, we also computed effect sizes as these are independent of sample size. Second, the clinical sample consisted of children suffering from a range of psychiatric disorders, and though for instance cortisol secretion and sleep did not significantly differ between the clusters of psychiatric disorders, larger samples might have brought out further differentiations between them. Therefore, relying on means for the clinical sample as a whole might have obscured some further underlying differences. Third, only children and parents who were willing and able to follow the entire study protocol volunteered to participate in the study; therefore, a positive selection bias cannot be excluded. Fourth, the present pattern of results may reflect the influence of other unassessed latent variables. In this regard, unfortunately, medication records for children of the clinical sample were incomplete; perhaps, a more thorough medication record would have brought out further results. Fifth, the cross-sectional design precludes conclusive answers about causal relationships. This holds particularly true when focusing on the "triad" of increased cortisol secretion, poor sleep and poor psychological functioning. Sixth, relative to healthy controls, children with psychiatric disorders reported being bullied and victimized more; therefore, future research might also focus in more detail on children's interactional behavior and social competences.

\section{Conclusions}

Compared to healthy controls, children with psychiatric disorders showed poor sleep, poor psychosocial behavior (psychological functioning) and greatly increased HPA AA. This pattern of results is 
already apparent in 5-years old pre-schoolers and suggests an increased risk for persistent psychiatric disorder in later life.

\section{Role of funding}

The present study was financially supported by the Swiss National Foundation (SNF: 32-68193.02 (M.H.); 32-49634.96 and 32-66778.01 (K.v.K.)) and the Jacobs Foundation Switzerland (MH). The SNF and the Jacobs Foundation had no further roles in the analysis and interpretation of the data, the writing report, and in the decision to submit the paper for publication.

\section{Contributors}

$\mathrm{MH}, \mathrm{SB}, \mathrm{SP}, \mathrm{AvW}, \mathrm{KvK}, \mathrm{SS}$, and EHT designed the study and wrote the protocol, and all of them managed the literature searches and analyses. SB, SP, SS and AvW were highly engaged with data collection and data entry. SB undertook the statistical analyses, and SP the statistical check. SB wrote the draft of the manuscript and coordinated the integration of the different comments and corrections of the authors. MH and EHT are the SB's senior researchers. KvK is the responsible senior researcher of SP, SS and AvW. All authors contributed to and have approved the final manuscript.

\section{Conflict of interest}

All authors declare that they have no conflicts of interest.

\section{Acknowledgments}

We thank R. Hartmann, C. Keppler, L. Kohler, B. Krebs, and P. Walter for their support in data collection. A special thank is due to $M$. König and V. Djurdjevic for technical support and data elaboration. Additionally, we are deeply grateful to Annemie Fritzen and Celine Pleimling-Franzen of the laboratory of the University of Trier (Germany) for saliva cortisol analyses. Moreover, we thank Nick Emler (Surrey, UK) who assisted with the proofreading of the manuscript. Finally, we thank all participating children, parents, and kindergarten teachers for their support of the study.

\section{References}

Acebo $C$, Sadeh A, Seifer R, Tzischinsky $O$, Wolfson AR, Hafer A et al Estimating sleep patterns with activity monitoring in children and adolescents: how many nights are necessary for reliable measures? Sleep 1999:22:95-103.

Baglioni C, Spiegelhalder K, Lombardo C, Riemann D. Sleep and emotions: a focus on insomnia. Sleep Medicine Reviews 2010;14:227-38.

Born J, Hansen K, Marshall L, Mölle M, Fehm HL. Timing the end of nocturnal sleep. Nature 1999:397:29-30.

Brand $S$, Annen $H$, Holsboer-Trachsler $E$, Blaser A. Intensive two-day cognitivebehavioral intervention decreases cortisol secretion in soldiers suffering from specific phobia to wear protective mask. Journal of Psychiatric Research 2011a; $45: 1337-45$

Brand S, Furlano R, Sidler M, Schulz J. Holsboer-Trachsler E. 'Oh, baby, please don't cryl': in infants suffering from infantile colic hypothalamic-pituitaryadrenocortical axis activity is related to poor sleep and increased crying adrenocortical axis activity is related to poor
intensity. Neuropsychobiology $2011 \mathrm{~b} ; 64: 15-23$.

Brand $S$, Kirov $R$. Sleep and its importance in adolescence and in common adolescent somatic and psychiatric conditions. International Journal of General Medicine 2011:4:425-42.

Brand S, Wilhelm FH, Kossowsky J, Holsboer-Trachsler E, Schneider S. Children suffering from separation anxiety disorder (SAD) show increased HPA axis activity compared to healthy controls. Journal of Psychiatric Research $2011 \mathrm{c} ; 45$ : activity

Buckley TM, Schatzberg AF. Review: on the interactions of the hypothalamicpituitary-adrenal (HPA) axis and sleep: normal HPA axis activity and circadian rhythm, exemplary sleep disorders. Journal of Clinical Endocrinology \& Metabolism 2005:90:3106-14.

Buske-Kirschbaum A, Jobst S, Wustmans A, Kirschbaum C. Rauh W, Hellhammer D. Attenuated free cortisol response to psychosocial stress in children with atopic dermatitis. Psychosomatic Medicine 1997:59:419-26.
Cohen J. Statistical power analysis for the behavioral sciences. Hilsdale, NJ: Lawrence Erlbaum Associates: 1988.

Cortese S, Konofal E, Yateman N. Mouren MC, Lecendreux M. Sleep and alertness in children with attention-deficit/hyperactivity disorder: a systematic review of the literature. Sleep 2006:29:504-11.

Crabtree VM, Dayyat E. Millis BC. Molfese DL. Effect of sleep restriction on children's cognitive and behavioural functioning. In: Presented at the 3rd annual pediatric sleep medicine meeting: 2007. March 2007, Amelia Island, Florida.

Dahl RE. Lewin DS. Pathways to adolescent health sleep regulation and behavior. Journal of Adolescent Health 2002;31:175-84

Dang-Vu TT, Desseilles M, Peigneux P. Maquet P. A role for sleep in brain plasticity. Pediatric Rehabilitation 2006:9:98-118.

Dayyat EA, Spruyt K, Molfese DL, Gozal D. Sleep estimates in children: parental versus actigraphic assessments. Nature and Science of Sleep 2011:3:115-23.

De Kloet ER, Vreugdenhil E, Oitzl MS, Joëls M. Brain corticosteroid receptor balance in health and disease. Endocrine Review 1998:19:269-301.

Dressendoerfer RA, Kirschbaum C, Rolyde W. Stahl F. Strasburger CJ. Synthesis of a cortisol-biotin conjugate and evaluation as a tracer in an immunoassay for salivary cortisol measurement. Journal of Steroid Biochemistry and Molecular Biology 1992:43:683-92.

Drummond SPA, Brown GG, Stricker JL. Buxton RB. Wong EC, Gillin JC. Sleep deprivation-induced reduction in cortical functional response to serial subtraction. NeuroReport 1999;10:3745-8.

El-Sheikh $M$. Buckhalt JA. Mark Cummings $E_{1}$ Keller P. Sleep disruptions and emotional insecurity are pathways of risk for children. Journal of Child Psychology and Psychiatry 2007;48:88-96.

Engel GL The need for a new medical model: a challenge for biomedicine. Science $1977 ; 196: 129-36$

Flinn MV, England BG. Social economics of childhood glucocorticoid stress response and health. American Journal of Physiological Anthropology 1997;102:33-53.

Forsythe Al, Keenan TA, Organick El, Stenberg W. Computer science: a first course. New York: Wiley; 1969.

Giedd JN. The teen brain: insights from neuroimaging. Journal of Adolescent Health 2008; $42: 335-43$.

Goodman R. The strength and difficulties questionnaire: a research note. Journal of Child Psychology and Psychiatry and Allied Disciplines 1997;38:581-6. The German questionnaire was downloaded from, www.sdquifo.com/d11.html.

Gorny SW, Allen RP, Krausmann DT, Cammarata J, Earley CJ. A parametric and sleep hysteresis approach to assessing sleep and wake from wrist activity meter with enhanced frequency range. In: Paper presented at the 11 th annual meeting of the associated professional sleep societies; 1997. June 10-15. San Francisco, CA.

the associated professional sleep societies; 1997. June 10-15. San Francisco, CA.
Granger DA, Weisz JR, McCracken JT, Ikeda SC, Douglas P. Reciprocal influences among adrenocortical activation, psychosocial processes, and the behavioral adjustment of clinic-referred children. Child Development 1996:67:3250-62.

Gregory AM, Caspi A, Eley TC, Moffitt TE, Ocomnor TG. Poulton R. Prospective longitudinal associations between persistent sleep problems in childhood and anxiety and depression disorders in adulthood. Journal of Abnormal Child Psychology 2005:33:157-63.

Gregory AM, Caspi A, Moffitt TE, Poulton R. Sleep problems in childhood predict neuropsychological functioning in adolescence. Pediatrics 2009;123:1171-6.

Gregory AM, Sadeh A. Sleep, emotional and behavioral difficulties in children and adolescents. Sleep Medicine Reviews; 2011.

Gromov I, Gromov D. Sleep and substance use and abuse in adolescents. Child and Adolescent Psychiatric Clinic of North America 2009;18:929-46.

Haitigan JD, Roisman Cl. Susman EJ. Barnett-Walker K, Monahan KC. Elevated trajectories of externalizing problems are associated with lower awakening cortisol levels in midadolescence. Developmental Psychology 2011:47:472-8.

Hatzinger M. Brand S, Perren S, Stadelmann S, von Wyl A, von Klitzing K, et al. Electroencephalographic sleep profiles and hypothalamic-pituitaryadrenocortical (HPA)-activity in kindergarten children: early indication of poor sleep quality associated with increased cortisol secretion. Joumal of Psychiatric Research $2008: 42: 532-43$.

Hatzinger M, Brand S, Perren S, Stadelmann S, von Wyl A, von Klitzing K, et al. Sleep actigraphy pattern and behavioral/emotional difficulties in kindergarten chitdren: association with hypothalamic-pituitary-ddrenocortical (HPA) activity. Journal of Psychiatric Research 2010;44:253-61.

Hatzinger $M$, Brand S, Perren S, von Wyl A, von Klitzing $K$. Holsboer-Trachsler E. Hypothalamic-pituitary-adrenocortical (HPA) activity in kindergarten children: importance of gender and associations with behavioral/emotional difficulties. Journal of Psychiatric Research 2007:41:861-70.

Heiler S, Legenbauer T, Bogen T, Jensch T, Holtmann M. Severe mood dysregulation: in the "light" of circadian functioning. Medical Hypotheses 2011:77:692-5.

Heim C, Mletzko T. Purselle D, Musselman DL, Nemeroff CB. The dexamethasone/ corticotropin-releasing factor test in men with major depression: role of childhood trauma. Biological Psychiatry 2008:15(63):398-405.

Heuser I, Yassouridis A, Holsboer F. The combined dexamethasone/CRH test a refined laboratory test for psychiatric disorders. Journal of Psychiatric Research 1994;28:341-56

Holsboer $F$, Ising $M$. Stress hormone regulation; biological role and translation into therapy. Annual Revue of Psychology 2010;61:81-109.

Holtmann M, Duketis E. Poustka L, Zepf FD, Poustka F, Bölte S. Bipolar disorder in children and adolescents in Germany: national trends in the rates of inpatients, 2000-2007. Bipolar Disorders 2010;12:155-63.

Hori H, Teraishi T, Sasayama D, Ozeki Y. Matsuo J, Kawamoto Y, et al. Poor sleep is associated with exaggerated cortisol response to the combined dexamethasone/ 
CRH test in a non-clinical population. Journal of Psychiatric Research 2011;45: 1257-63.

Iva nenko A. Slcep and psychiatric disorders in children and adolescents. New York NY: Informa Healthcare: 2008.

Jan JE, Reiter RJ, Bax MC, Ribary U. Freeman RD, Wasdell MB. Long-term sleep disturbances in children: a cause of neuronal loss. European Journal of Paediatric Neurology 2010;14:380-90.

Jezova $D$. Hlavacova $N$. Endocrine factors in stress and psychiatric disorders: focus on anxiety and salivary steroids. Annals of the New York Academy of Science 2008;1148:495-503.

Kagan J, Reznick S, Snidman N. Biological bases of childhood shyness. Science 1988; $240: 167-71$

Kirov R. Banaschewski T, Uebel H. Kinkelbur J, Rothenberger A. REM-sleep alterations in children with co-existence of tic disorders and attention-deficit/ hyperactivity disorder: impact of hypermotor symptoms. European Child and Adolescent Psychiatry 2007;16(Suppl. 1):45-50.

Kirov R, Brand S. The memory, cognitive and psychological functions of sleep: update from electroencephalographic and neuroimaging studies. "Neurointaging/Book 3"; ISBN 979-953-307-238-7; 2011.

Kirov R, Uebel H, Albrecht B. Banaschewksi T, Rothenberger A. Two faces of REM sleep in normal and psychopathological development. European Psychiatry 2011:26(Suppl. 1):422-3.

Koffel E, Watson D. The two-factor structure of sleep complaints and its relation to depression and anxiety. Journal of Abnormal Psychology 2009;118:183-94.

Lofthouse N. Gilchrist R, Splaingard M. Mood-related sleep problems in children and adolescents. Child and Adolescent Psychiatric Clinic of North America 2009;18:893-916.

Lopez-Duran NL, Kovacs M, George CJ. Hypothalamic-pituitary-adrenal axis dysregulation in depressed children and adolescents: a meta-analysis. Psychoneuroendocrinology 2009;34:1272-83.

Lorbetg B, Wilens TE, Martelon M, Wong P, Parcell $T$. Reasons for substance use among adolescents with bipolar disorder. American Journal of Addiction 2010; 19:474-80.

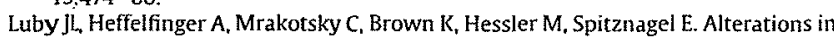
stress cortisol reactivity in depressed preschoolers relative to psychiatric and nodisorder comparison groups. Archives of General Psychiatry 2003;60:1248-55.

Lund $H G$. Reider BD, Whiting AB. Prichard JR. Sleep patterns and predictors of disturbed sleep in a large population of college students. Journal of Adolescent Health 2010;46:124-32

McFarlane AC, Barton CA, Yehuda R, Wittert G. Cortisol response to acute trauma and risk of posttraumatic stress disorder. Psychoneuroendocrinology 2011;36: $720-7$.

McLay RN, Klam WP, Volkert SL Insomnia is the most commonly reported symptom and predicts other symptoms of post-traumatic stress disorder in U.S. service members retuming from military deployments. Military Medicine 2010;175:759-62.

Measelle JR, Ablow JC, Cowan PA, Cowan CP. Assessing young children's views of their academic, social and emotional lives: an evaluation of the self-perception scales of the Berkeley Puppet Interview. Child Development 1998:69:1556-76.

Moss HB, Vanyukov MM, Marti CS. Salivary cortisol responses and the risk for substance abuse in prepubertal boys. Biological Psychiatry 1995:38:547-55.

Murray G, Harvey A. Circadian thythms and sleep in bipolar disorder. Bipolar Disorders 2010;12:459-72.

Muzur A. Pace-Schott EF, Hobson JA. The prefrontal cortex in sleep. Trends in Cognitive Sciences 2002;6:475 -81.

Nachmias M, Gumar M, Mangelsdorf S, Parritz RH. Buss K. Behavioral inhibition and stress reactivity: the moderating role of attachment security. Clild Development $1996: 67: 508-22$

Patterson GR, DeBaryshe BD, Ramsey E. A developmental perspective on antisocial behavior. American Psychologist 1989;44:329-35

Paus T, Kashavan M. Giedd JN. Why do many psychiatric disorders emerge during adolescence? Nature Review Neuroscience 2008;9:947-57.

Peirano PD, Algarin CR. Sleep in brain development. Biological Research 2007;40: 471-8.

Perlis ML, Giles D, Mendelson WB. Bootzin RR, Wyatt JK. Psychophysiological insomnia: the behavioural model of a neurocognitive perspective. Journal of Sleep Research 1997;6:179-88.

Pesonen AK, Kajantie E. Jones A. Pyhälä R, Lahti J, Heinonen K, et al. Symptoms of attention deficit hyperactivity disorder in children are associated with cortisol responses to psychosocial stress but not with daily cortisol levels. Journal of Psychiatric Research 2011:45:1471-6.

Pillai V. Kalmbach DA, Ciesla JA. A meta-analysis of electroencephalographic sleep in depression: evidence for genetic biomarkers. Biological Psychiatry 2011;15: 912-9.

Pruessner JC. Wolf OT, Hellhammer DH, Buske-Kirschbaum A, von Auer $\mathrm{K}$, Jobst $\mathrm{S}$, et al. Free cortisol levels after awakening: a reliable biological marker for the assessment of adrenocortical activity. Life Sciences 1997;61:2539-49.
Räikkönen K, Matthews KA, Pesonen AK, Pyhälä R, Paavonen EJ. Feldt K, et al. Poo sleep and altered hypothalamic-pituitary-adrenocortical and sympathoadrenal-medullary system activity in children. Journal of Clinical Endocrinology \& Metabolism 2010:95:2254-61.

Riemann D, Spiegelhalder K, Feige B. Voderholzer U, Berger M. Perlis M, et al. The hyperarousal model of insomnia: a review of the concept and its evidence. Sleep Medicine Reviews 2010;14:19-31.

Russ SJ. Herbert J. Cooper P. Gunnar MR, Goodyer I, Croudace T, et al. Cortisol levels in response to starting school in children at increased risk for social phobia. Psychoneuroendocrinology, in press.

Sadeh A, Lavie P, Scher A. Tirosh E, Epstein R. Actigraphic home-monitoring sleepdisturbed and control infants and young children: a new method for pediatric assessment of sleep-wake patterns. Pediatrics 1991:87:494-9.

Sadeh A, Raviv A, Gruber R. Sleep patterns and sleep disruptions in school-age children. Developmental Psychology 2000;36:291-301.

Scheffé H. Practical solutions to the Behrens-Fisher problem. Journal of the American Statistical Association 1970;65:1501-8.

Schmidt LA. Fox NA. Rubin KH, Sternberg EM, Gold PW. Smith CC et al Behavioral and neuroendocrine responses in shy children. Developmental Psychobiology $1997 ; 30: 127-40$.

Schüle C. Baghai T. Zwanzger P. Minov C. Padberg F, Rupprecht R. Sleep deprivation and hypothalamic-pituitary-adrenal (HPA) axis activity in depressed patients. Journal of Psychiatric Research 2001;35:239-47.

Silk IS, Vanderbilt-Adrianc E, Shaw DS, Forbes EE, Whalen DA, Ryan ND, et al Resilience among children and adolescents at risk for depression: mediation and moderation across social and neurobiological contexts. Development and Psychopathology 2007:19:841-65.

Smith MT, Huang MI, Manber R. Cognitive behavior therapy for chronic insomnia occurring within the context of medical and psychiatric disorders. Clinica Psychology Revue 2005:25:559-92.

Sourander A, Ronning J, Brunstein-Klomek A, Gyllenberg D, Kumpulainen $k$ Niemelä $S$, et al. Childhood bullying behavior and later psychiatric hospital and psychopharmacologic treatment: findings from the Finnish 1981 birth cohort study. Archives of General Psychiatry 2009;66:1005-12.

Stadler C, Kroeger A, Weyers P, Grasmann D. Horschinek M. Freitag C, et al. Cortisol reactivity in boys with attention-deficit/hyperactivity disorder and disruptive behavior problems: the impact of callous unemotional traits. Psychiatry Research 2011:187:204-9.

Steen NE, Methlie P, Lorentzen S, Hope S, Barrett EA, Larsson $S$, et al. Increased systemic cortisol metabolism in patients with schizophrenia and bipolar disorder: a mechanism for increased stress vulnerability? Journal of Clinica Psychiatry 2011:72:1515-21.

Steiger A. Neurochemical regulation of sleep. Journal of Psychiatric Research 2007 $41: 537-52$

Tran KD, Nguyen CD, Weedon J, Goldstein NA. Child behavior and quality of life in pediatric obstructive sleep apnea. Archives of Otolaryngology - Head and Neck Surgery $2005 ; 131: 52-7$.

Von Klitzing K, Kelsay K. Emde RN. The structure of 5-yeat-old children's play narratives within the MacArthur Story Stem Methology. In: Emde RN, Wolf DP, Oppenheim D, editors. Revealing the inner world of children: the MacArthur Story Stem Battery and parent-child narratives. New York: Oxford University Story Stem Battery and
Press; 2003. p. $106-28$.

Watamura SE, Donzella B, Alwin J, Gunnar MR. Morning-to-afternoon increases in cortisol concentrations for infants and toddlers at child care: age differences and behavioral correlates. Child Development 2003;74:1006-20.

Welch BL. The generalization of "Student's" problem when several different population variances are involved. Biometrika 1947:34:28-35.

Werner $H$, Molinari L, Guyer $C$, Jenni $O G$. Agreement rates between actigraphy diary. and questionnaire for children's sleep patterns. Archives of Pediatric and Adolescent Medicine 2008;162:350-8.

Wolkowitz OM, Epel ES, Reus VI, Mellon SH. Depression gets old fast: do stress and depression accelerate cell aging? Depression and Anxiety 2010:27:327-38.

Wong MM, Brower KJ, Fitzgerald HE, Zucker RA. Sleep problems in early childhood and early onset of alcohol and other drug use in adolescence. Alcoholism, Clinical Experimental Research 2004;28:578-87.

Yoo S, Gujar N, Hu P, Jolesz FA, Walker MP. The human emotional brain without sleep - a prefrontal amygdala disconnect. Current Biology 2007:17:877-8.

Zahn-Waxler C, Klimes-Dougan B, Slattery M. Internalizing disorders of childhood and adolescence: progress and prospects for advances in understanding anxiety and depression. Development and Psychopathology 2000:12:443-66.

Zeiders KH, Doane LD, Adam EK. Reciprocal relations between objectively measured sleep patterns and diumal cortisol rhythms in late adolescence. Journal of Adolescent Health 2011:48:566-71.

Zhang J, Lam SP, Li SX, Li AM, Lai KY, Wing YK. Longitudinal course and outcome of chronic insomnia in Hong Kong Chinese children: a 5-year follow-up study of a community-based cohort. Sleep 2011;34:1395-402. 